\title{
Low Vitamin D Levels at Birth and Early Respiratory Outcome in Infants With Gestational Age Less Than 29 Weeks
}

OPEN ACCESS

Edited by:

Ömer Erdeve,

Ankara University, Turkey

Reviewed by:

Gamze Demirel,

Istanbul Medipol University, Turkey

Prem Fort,

Johns Hopkins All Children's Hospital,

United States

*Correspondence:

Farid Boubred

farid.boubred@ap-hm.fr

tThese authors have contributed equally to this work and share first authorship

Specialty section:

This article was submitted to Neonatology,

a section of the journal

Frontiers in Pediatrics

Received: 07 October 2021 Accepted: 11 November 2021

Published: 21 January 2022

Citation:

Papalia H, Samonini A, Buffat $C$ Gras E, des Robert C, Landrier J-F. Pauly V and Boubred F (2022) Low

Vitamin D Levels at Birth and Early Respiratory Outcome in Infants With Gestational Age Less Than 29 Weeks.

Front. Pediatr. 9:790839.

doi: 10.3389/fped.2021.790839

\begin{abstract}
Honoré Papalia ${ }^{1 \dagger}$, Anais Samonini ${ }^{1 \dagger}$, Christophe Buffat ${ }^{2}$, E. Gras ${ }^{1}$, Clotilde des Robert ${ }^{1}$, Jean-Francois Landrier ${ }^{3}$, Vanessa Pauly ${ }^{4}$ and Farid Boubred ${ }^{1,3 *}$

${ }^{1}$ Neonatal Unit, Hospital University La Conception, APHM, Marseille, France, ${ }^{2}$ Laboratory of Biochemistry and Molecular Biology, Hospital University la Conception, APHM, Marseille, France, ${ }^{3}$ Aix-Marseille University, INSERM, INRAE, C2VN, Marseille, France, ${ }^{4}$ EA 3279, CEReSS-Health Service Research and Quality of Life Center, Public Health and Medical Information Department, APHM, Marseille, France
\end{abstract}

Background: Vitamin D (VitD) is involved in lung development but its influence on respiratory distress syndrome of extremely preterm (EPT) infants have been little investigated. In this study, we examined the influence of low vitamin D status at birth on early respiratory outcomes of this vulnerable infant population.

Methods: Cord blood 25(OH)D levels $\leq 75 \mathrm{nmol} / \mathrm{L}$ were considered as Low vitamin D levels. Stepwise logistic regression and classification regression-tree analyses were used and the primary outcome was the combined outcome of death or mechanical ventilation need by the end of the first week (death or MV DoL7) as a marker od RDS severity.

Results: The mean (SD) GA and birth weight were 26 (1.4) weeks and 801 (212) gr, respectively; 81/109 (74\%) infants had low 25(OH)D levels. Infants with low VitD levels had $25 \%$ higher initial $\mathrm{FiO}_{2}$ levels $(p<0.05)$ and were more likely to be mechanically ventilated on DoL7 (36 vs. 7\%, $p<0.05$ ). Adjusted for gestational age, they had 10-fold higher odds of death or MV DoL7 $(p<0.01)$. By regression tree analysis, the rate of death or MV DoL7 increased from 18 to $71 \%$ in infants with GA $<26$ weeks and with cord blood 25(OH)D levels higher and lower than $74 \mathrm{nmol} / \mathrm{L}$, respectively $(p<0.05)$.

Conclusion: Low vitamin $\mathrm{D}$ levels at birth are associated with early adverse respiratory outcomes in infants with GA less 29 weeks. Further largest studies are needed to confirm this association.

Keywords: extremely preterm infants, RDS-respiratory distress syndrome, surfactant, vitamin D, bronchopulmonary dysplasia, LISA (less invasive surfactant administration), nasal CPAP (continuous positive airway pressure), SGA (samll for gestational age)

\section{INTRODUCTION}

Respiratory distress syndrome (RDS) can be considered as a developmental disease which predominantly concerned extremely preterm (EPT) infants. These infants often have severe form of RDS with early high oxygen needs, multiple surfactant administration and prolonged mechanical ventilation. Early markers of RDS severity may help to better identify high risk infants and provide optimal care to prevent short and long term RDS complications such as bronchopulmonary dysplasia (BPD). 
Vitamin D is well known for its major role in fetal bone metabolism, but recent evidence also shows a biological role in normal lung development and in surfactant synthesis (14). In animals, maternal gestational vitamin D depletion affects fetal lung development with reduced alveolar numbers and impaired bronchial structure $(2,4)$. Children born to vitamin Ddeficient mothers are more likely to have respiratory symptoms such as wheezing events, asthma, respiratory tract infections or lung dysfunction (5-9). In premature infants, with immature lungs, the optimal dose of vitamin D supply is still under investigation. The few randomized clinical studies looking into the effects of vitamin D supply on respiratory outcomes have shown variable effects with either no effects or decreased RDS severity (10-12).

Preterm infants are at high risk of vitamin $\mathrm{D}$ deficiency at birth, with observational studies showing a prevalence as high as $90 \%(13-15)$. A part of that deficient state may result from limited vitamin $\mathrm{D}$ transfer from the mother. Indeed, the fetus entirely depends on the maternal vitamin $\mathrm{D}$ status, and placental transfer mainly occurs in the third trimester (16). Furthermore, the leading obstetrical causes of prematurity, including preeclampsia, gestational diabetes, small for gestational age (SGA) and threatened preterm delivery, are often associated with maternal vitamin $\mathrm{D}$ deficiency (17-19). However, the adverse effects of maternal/fetal vitamin D deficiency on neonatal outcomes remain conflicting in very preterm infants and still need to be further investigated in extremely preterm (EPT) infants, in particular.

The objective of the study was to examine the association between vitamin $\mathrm{D}$ status at birth and early respiratory outcomes of infants with GA $<29$ weeks.

\section{METHODS}

This observational and retrospective study included preterm infants born with GA between 24 weeks $^{+0}$ and 28 weeks $^{+6}$ between November 1, 2018 and April 31, 2020 that were admitted to the Neonatal Intensive Care Unit (NICU), Hospital University La Conception, Marseilles, France. This study was part of a quality improvement initiative aimed at optimizing vitamin $\mathrm{D}$ supplementation in preterm infants. All infants followed the same postnatal vitamin $\mathrm{D}$ supply protocol during the study period; no changes have been made between the two groups. Blood 25 hydroxyvitamin D [25(OH)D] concentration was measured at birth from umbilical cord blood. This study was approved by local ethical and privacy health data protection committees ( $\mathrm{N}^{\circ}$. DSN_2019-06-20_7706). Clinical and biological data collection were anonymized. Parents were informed of the study and were not required to sign informed consent, but they could oppose data collection. For this study, preterm infants born at our institution and with specifically cord blood 25(OH)D measurements were eligible; infants with congenital or genetic abnormalities or whose parents refused to participate in the study were excluded. Cord blood $25(\mathrm{OH}) \mathrm{D}$ levels were determined by chemiluminescence (Roche
Diagnostics, Mannheim, Germany). This method has been calibrated to liquid chromatography-mass spectrometry. In preterm infants, the optimal $25(\mathrm{OH}) \mathrm{D}$ levels for adequate respiratory outcome are unknown. We used the Endocrine Society recommendations for defining vitamin $\mathrm{D}$ status that are made for healthy bone growth (20). For this study, two groups of infants were compared: infants with cord blood 25(OH)D levels $\leq 75 \mathrm{nmol} / \mathrm{L}$ (LowVitD status group) and infants with cord blood $25(\mathrm{OH}) \mathrm{D}$ levels $>75 \mathrm{nmol} / \mathrm{L}$ (SufficientVitD status).

\section{Early Respiratory Outcome}

The primary outcome was the combined outcome of death in the first week of life or the need for mechanical ventilation (MV) on day of life (DoL) 7 (death or MV DoL7). We also compared other respiratory outcomes, such as delivery room intubation within 15 mins of life (MV DR), need for MV on DoL3 (MV DoL3) and 7 (MV DoL7) and any need for MV in the first week of life (MV W1). Respiratory management was standardized; all spontaneously breathing infants were initially managed with nasal continuous positive airway pressure (NCPAP). Surfactant was indicated when the fractional inspired oxygen concentration $\left(\mathrm{FiO}_{2}\right)$ reached $30 \%$ or when the infant required mechanical ventilation $(21,22)$. Observational studies have confirmed that $\mathrm{FiO}_{2}$ exceeding 0.30 in infants initially managed on NCPAP for RDS predicted NCPAP failure (22). Timing and $\mathrm{FiO}_{2}$ levels immediately before surfactant administration were collected. The less invasive surfactant administration (LISA) technique or surfactant administration after a brief intubation procedure (intubation, surfactant and extubation, INSURE procedure) were compared between the two groups.

\section{Data Collection and Statistical Analysis}

Maternal and neonatal outcomes were collected from infant medical charts. Gestational age (GA) was calculated from first trimester obstetrical ultrasound, and small for gestational age (SGA) was determined using Fenton growth charts (23). At birth, umbilical cord milking or delayed cord clamping for at least $30 \mathrm{~s}$ defined placental transfusion. Severe cerebral injury included stage 3 and 4 intraventricular hemorrhage (Papile's classification), periventricular leukomalacia and isolated ventricular dilatation at term. The variable of severe digestive disease included necrotizing enterocolitis (NEC) stage 2 or more (Bell's classification) and isolated intestinal perforation. Late onset sepsis after DoL3 and severe retinopathy (stage 3 and more) were noted as well. Bronchopulmonary dysplasia (BPD) was defined as the need for oxygen supplementation or respiratory support at 36 weeks postmenstrual age. We used Jensen et al.'s definition to classify BPD severity: infants who required nasal cannula flow rate $>2 \mathrm{~L} / \mathrm{min}$, non-invasive positive airway pressure, or invasive mechanical ventilation were classified as grade 2-3 BPD (24).

To compare both infant vitamin D status groups, we performed univariate statistical tests: Chi-squared (or Fischer's exact tests) and Student's $t$ tests (or Mann-Whitney test) were used as appropriate to compare groups for categorical and 
TABLE 1 | Obstetrical and neonatal characteristics according to vitamin D status at birth.

\begin{tabular}{|c|c|c|c|c|}
\hline Characteristics, n (\%) & $\begin{array}{c}\text { All } \\
\text { population } \\
(N=109)\end{array}$ & $\begin{array}{l}\text { SufficientVi } \\
\text { status } \\
(N=28)\end{array}$ & $\begin{array}{l}\text { LowVitD } \\
\text { status } \\
(N=81)\end{array}$ & $P$ value \\
\hline \multicolumn{5}{|l|}{ Obstetrical data } \\
\hline Multiple gestation & $29(27)$ & $8(28)$ & $21(26)$ & 0.78 \\
\hline PPROM & $21(19)$ & $5(18)$ & $16(20)$ & 0.82 \\
\hline Preeclampsia & $22(20)$ & $5(18)$ & $17(21)$ & 0.79 \\
\hline MTR/PA & $19(17)$ & $5(18)$ & $14(17)$ & 1.00 \\
\hline GD & $4(3.6)$ & $0(0)$ & $4(5)$ & 0.57 \\
\hline Chorioamnionitis & $25(23)$ & $5(18)$ & $20(25)$ & 0.60 \\
\hline Antenatal steroids & $85(78)$ & $22(78)$ & $63(78)$ & 0.93 \\
\hline $\mathrm{Mg}^{2+}$ sulfate & $81(74)$ & $23(82)$ & $58(72)$ & 0.27 \\
\hline Cesarean section & $88(81)$ & $20(71)$ & $68(84)$ & 0.68 \\
\hline \multicolumn{5}{|l|}{ Neonatal data } \\
\hline GA, mean (SD), weeks & $26(1.4)$ & $26.5(1.5)$ & $26(1.4)$ & 0.11 \\
\hline BW, mean (SD), g & $801(212)$ & 828 (198) & $792(217)$ & 0.40 \\
\hline SGA & $23(21)$ & $6(21)$ & $17(21)$ & 0.96 \\
\hline Female & $60(55)$ & $19(68)$ & $41(51)$ & 0.11 \\
\hline 5 min Apgar score $<7$ & $24(22)$ & $4(14)$ & $20(25)$ & 0.27 \\
\hline Placental transfusion & $66(60)$ & $19(68)$ & $47(58)$ & 0.17 \\
\hline Digestive disease & $8(7)$ & $3(11)$ & $5(6)$ & 0.42 \\
\hline Severe cerebral injury & $10(9)$ & $2(7)$ & $8(10)$ & 1.00 \\
\hline Early onset sepsis & $9(8)$ & $2(7)$ & $7(9)$ & 1.00 \\
\hline Late onset sepsis & $56(51)$ & $12(43)$ & $44(54)$ & 0.29 \\
\hline Treatment for PDA & $38(35)$ & $8(28)$ & $30(37)$ & 0.41 \\
\hline Severe ROP & 12/103 (12) & 2/26 (8) & 10/77 (13) & 0.72 \\
\hline BPD any grade & $59 / 97(61)$ & $12 / 25(48)$ & $47 / 72(65)$ & 0.12 \\
\hline BPD stage $2-3$ & $31 / 97(32)$ & $5 / 25(20)$ & $26 / 72(36)$ & 0.21 \\
\hline Death before discharge & $12(11)$ & $3(11)$ & $9(11)$ & 1.00 \\
\hline
\end{tabular}

$B P D$, bronchopulmonary dysplasia; BW, birth weight (gr); GA, gestational age (weeks); GD, gestational diabetes mellitus; MTR/PA, metrorrhagia/placental abruption; PDA, patent ductus arteriosus; PPROM, preterm premature rupture of membranes; $R O P$, retinopathy of prematurity; SGA: small for gestational age; SufficientVitD status, infants with cord blood 25(OH)D levels > $75 \mathrm{nmol} / \mathrm{L}$; LowVitD status, infants with cord blood 25(OH)D levels $\leq 75 \mathrm{nmol} / \mathrm{L}$.

quantitative variables, respectively. All statistical tests were twosided. To analyze factors associated with the combined variable of death or MV DOL7, we performed univariate and multivariate logistic regression analyses. We included variables with $p<0.20$ in univariate analyses into a step-by-step backward multivariable analysis. We also used Firth's penalized estimation using logistic regression to account for the low number, which led to imprecisions in parameter estimation. The results are presented as odds ratios (ORs) and their 95\% confidence intervals (CIs).

Then, as an explanatory analysis, we performed a classification regression tree analysis (CART) to identify an easy-tounderstand algorithm for predicting the primary outcome of death or MV at DoL7. This analysis allows automatic selection of categorical variables and of optimal cutoff points of continued variables and generates a classification tree when the more important variable in relation to outcome is at the top of the
TABLE 2 | Early respiratory outcomes according to vitamin D status at birth.

\begin{tabular}{|c|c|c|c|c|}
\hline Characteristics, $n(\%)$ & $\begin{array}{c}\text { All } \\
\text { population } \\
(N=109)\end{array}$ & $\begin{array}{l}\text { SufficientVitD } \\
\text { status } \\
(N=28)\end{array}$ & $\begin{array}{l}\text { LowVitD } \\
\text { status } \\
(N=81)\end{array}$ & $P$ value \\
\hline Surfactant & $83(76)$ & $21(75)$ & $62(76)$ & 0.87 \\
\hline Timing $(\min )^{*}$ & $50(25-90)$ & $62(30-90)$ & $41(25-60)$ & 0.09 \\
\hline $\mathrm{FiO}_{2}(\%)$, mean (SD) & $51(22)$ & $41(18)$ & $54(22)$ & 0.02 \\
\hline$\geq 2$ doses & $19(17)$ & $3(11)$ & $16(20)$ & 0.39 \\
\hline LISA/INSURE procedure & $46(42)$ & $14(50)$ & $32(39)$ & 0.33 \\
\hline MV W1 & $52(48)$ & 9 (32) & $43(53)$ & 0.05 \\
\hline MV W1 duration (h)* & $\begin{array}{c}120 \\
(24-168)\end{array}$ & $\begin{array}{c}72 \\
(15-144)\end{array}$ & $\begin{array}{c}144 \\
(14-168)\end{array}$ & 0.24 \\
\hline HFO & $21(40)$ & $1(11)$ & $20(46)$ & 0.06 \\
\hline MV DR & $24(39)$ & $4(14)$ & $20(25)$ & 0.30 \\
\hline MV DoL3 & $35(32)$ & $6(21)$ & 29/80 (36) & 0.15 \\
\hline MV DoL7 & $\begin{array}{c}28 / 106 \\
(26)\end{array}$ & $2(7)$ & 26/78 (33) & 0.007 \\
\hline Death or MV DoL7 & $31(28)$ & $2(7)$ & $29(36)$ & 0.003 \\
\hline
\end{tabular}

*Median (IQR); HFO, high frequency oscillation; MV W1, mechanical ventilation in the first week of life; MV DR, mechanical ventilation in the first 15 min after birth (delivery room); MV DoL3, mechanical ventilation on day of life 3; MV DoL7, mechanical ventilation on day of life 7; SufficientVitD status, infants with cord blood 25(OH)D levels > $75 \mathrm{nmol} / \mathrm{L}$; LowVitD status, infants with cord blood 25(OH)D levels $\leq 75 \mathrm{nmol} / \mathrm{L}$.

decision tree (25). Variables initially entered for consideration into the CART analysis were the following: GA, sex, multiple pregnancies, preterm premature rupture of membranes, chorioamnionitis, antenatal corticosteroid therapy, cesarean section, placental transfusion and cord blood 25(OH)D levels. This CART analysis was mainly performed to reveal an optimal threshold for blood 25(OH)D levels. Due to the low number of subjects involved in the analysis, it was performed on the whole dataset; the accuracy was tested using three-fold cross validation repeated 200 times. The analyses were performed using IBM SPSS Statistics for Windows (IBM Company, Chicago, IL, USA), Version 20.0, and SAS ${ }^{\circledR}$, Version 9.4 (SAS Institute Inc, Cary, NC, USA). In this study, $p<0.05$ were considered statistically significant. The CART tree was generated using the RPART package in $\mathrm{R}^{\circledR}$ Software.

\section{RESULTS}

During the study period, 112 infants met the eligibility criteria, and 3 infants were excluded: 2 for congenital and genetic anomalies and 1 for parental refusal (Supplementary Figure). The mean (SD) GA and birth weight were 26 (1.4) weeks and 801 (212) gr, respectively. The mean (SD) cord blood 25(OH)D level was 53 (32) nmol/L. A total of 81 (74\%) infants had low cord blood 25(OH)D levels ( $\leq 75 \mathrm{nmol} / \mathrm{L})$ and $56(51 \%)$ infants had cord blood 25(OH)D levels $<50 \mathrm{nmol} / \mathrm{L}$.

Obstetrical and neonatal characteristics, in particular GA, birth weight, SGA, sex ratio and exposure to antenatal corticosteroids, were comparable between infants with low and sufficient cord blood 25(OH)D levels (Table 1). However, early respiratory outcomes differed between the two groups of infants 


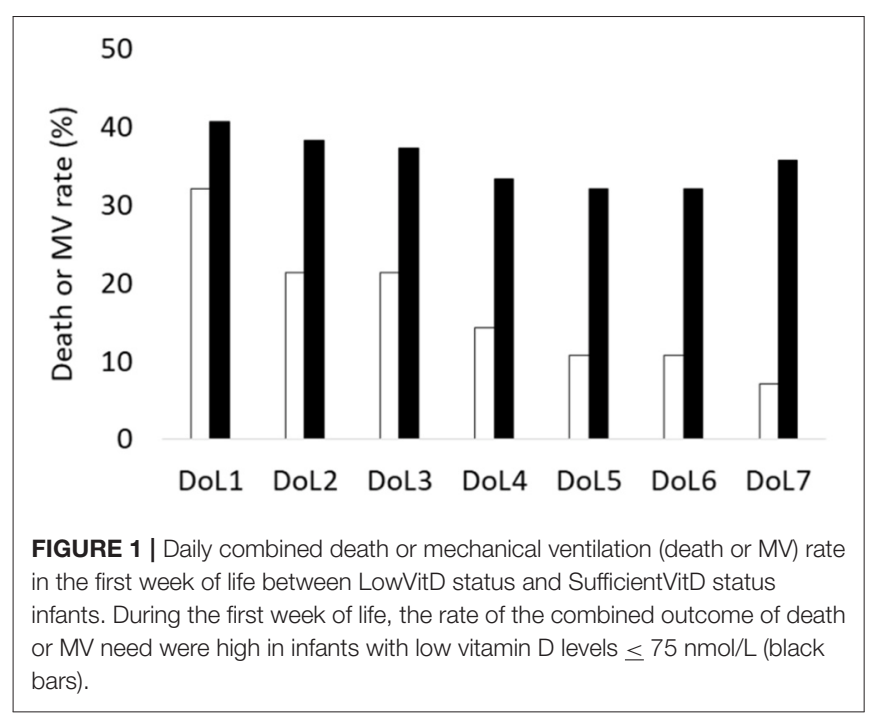

TABLE 3 | Regression analysis: factors associated with the combined outcome of death or mechanical ventilation on the 7th day after birth (death or MV DOL7).

\begin{tabular}{lcc}
\hline & Adjusted OR (95\%IC) & $\boldsymbol{P}$ value \\
\hline GA & $0.39(0.25-0.60)$ & $<0.0001$ \\
LowVitD status & $10.6(1.13-65.1)$ & 0.01 \\
\hline
\end{tabular}

GA, gestational age (weeks); LowVitD status, infants with cord blood 25(OH)D levels $\leq$ $75 \mathrm{nmol} / \mathrm{L}$.

(Table 2). The timing, dose number and technique procedure (LISA or INSURE) of surfactant administration were not different, but $\mathrm{FiO}_{2}$ levels at the time of surfactant administration were $25 \%$ higher in LowVitD status infants $(p=0.02)$. At DoL7, the rate of the combined outcome of death or $\mathrm{MV}$ requirement was higher in LowVitD status infants (36 vs. $7 \%, p<0.01$ ). These infants were also more likely to receive MV during the first week (MV W1) (53 vs. $32 \%, p=0.05$ ) than the group of SufficientVitD status infants (Figure 1) and tended to be more frequently ventilated by high frequency oscillation (46 vs. $11 \%, p$ $=0.06$ ). At DoL7, 93\% of infants who died or needed MV were from the LowVitD status group.

In the multivariate analyses, and after backward elimination of variables, adjusted for GA, infants with LowVitD status had higher odds of death or being mechanically ventilated at DoL7 with an adjusted OR (95\% CI) of $10.6(1.13-65.1)(p<0.05)$ (Table 3). The same association was found with the outcome of MV DoL7 with an adjusted (on GA) OR (95\% CI) of 8.14 (1.37-48.5) $(p<0.05)$.

The CART analysis revealed GA, with the threshold value at 26 weeks, and cord blood $25(\mathrm{OH}) \mathrm{D}$ levels $<74 \mathrm{nmol} / \mathrm{L}$ were important variables to predict the combined outcome of death or VM DoL7 (Figure 2). The rate was $10 \%$ in infants with GA above 26 weeks and reached $71 \%$ in infants with GA $<26$ weeks who had cord blood 25(OH)D levels lower than $74 \mathrm{nmol} / \mathrm{L}$. The mean accuracy of this algorithm was estimated to be equal to 0.77 CI $95 \%$ [0.64-0.89].

\section{DISCUSSION}

In this study, we found an association between vitamin $\mathrm{D}$ status at birth and early respiratory outcome in infants with GA $<29$ weeks. Infants who had low blood $25(\mathrm{OH}) \mathrm{D}$ levels $\leq 75 \mathrm{nmol} / \mathrm{L}$ at birth had early adverse outcomes with higher oxygen need for RDS and prolonged mechanical ventilation by the end of the first week of life compared to their counterparts that had adequate blood vitamin D levels.

Studies that evaluated the influence of vitamin D status on early respiratory outcome of very preterm infants have shown conflicted findings $(15,26-28)$. The makers used to define RDS severity and vitamin D deficiency varied between the studies. Some of them have found a high rate of RDS and markers of severe respiratory disease while others did not (15, 26-30). Onwuneme $\mathrm{C}$ et al. have found in a population of very preterm infants ( $\mathrm{GA}<32$ weeks) an association between vitamin $\mathrm{D}$ deficiency at birth $[25(\mathrm{OH}) \mathrm{D}$ levels $<30 \mathrm{nmol} / \mathrm{L}]$ and clinical signs of acute respiratory morbidity with higher oxygen needs and a greater rate of MV in the delivery room and during the neonatal period (15). We also found higher $\mathrm{FiO}_{2}$ levels at surfactant administration while the timing to administration tended to be shorter, and higher need of high frequency oscillation; these results can be considered marker of respiratory disease severity. In contrast to these previous studies, we included a population of more premature infants who are particularly vulnerable to a severe form of RDS with high needs of intubation and prolonged mechanical ventilation. We also included infants with higher prevalence (26\%) of sufficient vitamin D concentrations (above $75 \mathrm{nmol} / \mathrm{L}$ ); while this prevalence was usually reported $<5-10 \%$. Including infants with higher cord blood 25(OH)D levels may have revealed the adverse consequences of vitamin $\mathrm{D}$ deficiency in our study. Our study adds further evidence on the influence of vitamin D status at birth on early respiratory outcomes in preterm infants.

Although we used the international vitamin $\mathrm{D}$ definition to classify infants, the CART analysis identified optimal cutoff points for $25(\mathrm{OH}) \mathrm{D}$ of $74 \mathrm{nmol} / \mathrm{L}$, which is the threshold level commonly used in pediatric and adult medicine to define vitamin D sufficiency (20). In this method, the more important variables are ranked early on the classification tree, showing the important influence of vitamin D on early respiratory outcome, especially in infants with GA $<26$ weeks; the rate of death or MV DoL7 fourfold increased between SufficientVitD infants and their counterpart infants who had low 25(OH)D levels $(p$ $<0.05)$. While the adequate vitamin $\mathrm{D}$ status is unknown in preterm infants; our study provides useful insights on the optimal 25(OH)D levels at birth.

Recent evidence suggests a biological role of vitamin $\mathrm{D}$ in normal lung development and maturation (2, 4, 30, 31). Vitamin $\mathrm{D}$ also contributes to surfactant synthesis and secretion by alveolar type II cells (31). The fetus is exclusively dependent on maternal vitamin D status, and transfer from the mother mainly occurs during the third trimester. The umbilical cord blood $25(\mathrm{OH}) \mathrm{D}$ level at birth is therefore representative of fetal vitamin D stores. Endothelial and alveolar type II cells 


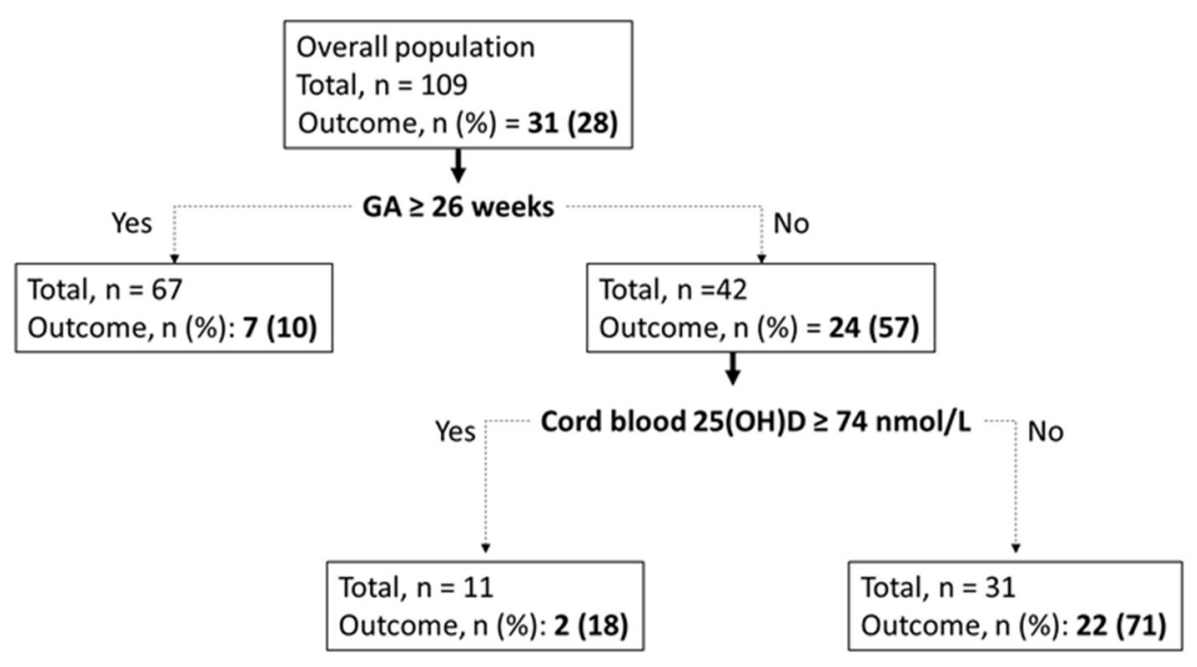

FIGURE 2 | CART model for death or MV DoL7 outcome. In each node (rectangle), the category "Outcome" refers to the presence of the combined outcome of death or MV DoL7, with $n$ and percentage of related infants.

express a nuclear receptor specific for the bioactive form of vitamin $\mathrm{D}\left[1,25(\mathrm{OH})_{2} \mathrm{D}_{3}\right]$, named vitamin $\mathrm{D}$ receptor (VDR). VDR response elements are also present in a subset of more than 500 genes involved in lung development in humans and rodents $(32,33)$. In animals, maternal gestational vitamin $\mathrm{D}$ depletion impairs fetal lung development with reduced alveolar numbers, decreased vascular density, altered pneumocyte type II differentiation, decreased tracheal size, and increased airway smooth muscle mass $(2,31)$. In the neonatal lungs of vitamin D-depleted rats, genes involved in the inflammatory response and vascular development, such as VEGF, have been found to be up- and downregulated, respectively (34). These functional and structural alterations are responsible for increased neonatal mortality with lower oxygen saturation, reported in preterm pups (35). In the long term, the offspring displayed increased airway resistance and low tidal volume (2). Some of these functional alterations, including frequent wheezing events, asthma, lung dysfunctions and respiratory tract infections, were also observed in children of vitamin D-deficient mothers (7-9). Finally, in rodents, maternal gestational vitamin $\mathrm{D}$ administration prevents neonatal mortality and lung injury induced by intrauterine exposure to endotoxin, which is a model of bronchopulmonary dysplasia (36). Based on these preclinical data, we can hypothesize that high oxygen and sustained MV needs for RDS observed in LowVitD status preterm infants result from delayed lung maturation.

This study had some intrinsic limitations due to the study design. Some commonly used markers of RDS severity such as respiratory severity score and ventilator settings are lacking; but high initial $\mathrm{FiO}_{2}$ levels, prolonged mechanical ventilation needs or frequently use of high frequency oscillation could be considered surrogate marker of RDS severity. Our sample size was too small to investigate the influence of vitamin D status at birth on other neonatal outcomes, especially BPD. Moreover, although our single-center experience may have limited bias linked to differences in health care practices, further multicenter studies with sufficient size are needed to confirm our findings.

In conclusion, in this study, we found that preterm infants with GA $<29$ weeks that had $25(\mathrm{OH})$ D levels at birth $\leq 75 \mathrm{nmol} / \mathrm{L}$ had early adverse outcomes. Our findings provide additional evidence for the important role of fetal vitamin $\mathrm{D}$ on lung development and provide new insights into optimal 25(OH)D levels. In very and extremely preterm infants early vitamin $\mathrm{D}$ status, and thus maternal vitamin D status, can be considered marker of respiratory disease including RDS and BPD. Early respiratory outcomes could be improved by preventing maternal gestational vitamin D deficiency. Larger studies should be performed to confirm these findings and to investigate the influence of vitamin D on other neonatal outcomes and especially on long-term respiratory functions.

\section{DATA AVAILABILITY STATEMENT}

The raw data supporting the conclusions of this article will be made available by the authors, without undue reservation.

\section{ETHICS STATEMENT}

The studies involving human participants were reviewed and approved by Assistance Publique des Hôpitaux de Marseille, Comission Informatique et Liberté. Written informed consent from the participants' legal guardian/next of kin was not required to participate in this study in accordance with the national legislation and the institutional requirements.

\section{AUTHOR CONTRIBUTIONS}

HP and AS collected data, drafted the initial manuscript, and reviewed and revised the manuscript. EG collected data and reviewed and revised the manuscript. CB collected data, 
carried out vitamin D analyses, and reviewed and revised the manuscript. CR designed the data collection instruments and reviewed and revised the manuscript. J-FL participated to analysis and interpretation of data and critically reviewed the manuscript for important intellectual content. VP designed the data collection instruments and carried out the statistical analyses. FB conceptualized and designed the study and reviewed and revised the manuscript. All authors approved the final

\section{REFERENCES}

1. DeLuca HF. Overview of general physiologic features and functions of vitamin D. Am J Clin Nutr. (2004) 80:689S-1696S. doi: 10.1093/ajen/80.6.1689S

2. Lykkedegn S, Sorensen GL, Beck-Nielsen SS, Christesen HT. The impact of vitamin $\mathrm{D}$ on fetal and neonatal lung maturation. A systematic review. Am J Physiol Lung Cell Mol Physiol. (2015) 308, L587-602. doi: 10.1152/ajplung.00117.2014

3. Chen L, Wilson R, Bennett E, Zosky GR. Identification of vitamin D sensitive pathways during lung development. Respir Res. (2016) 17:47. doi: 10.1186/s12931-016-0362-3

4. Wang P, Tan ZX, Fu L, Fan YJ, Luo B, Zhang ZH, et al. Gestational vitamin $\mathrm{D}$ deficiency impairs fetal lung development through suppressing type II pneumocyte differentiation. Reprod Toxicol. (2020) 94:40-7. doi: 10.1016/j.reprotox.2020.03.008

5. Thorsteinsdottir F, Cardoso I, Keller A, Stougaard M, Frederiksen P, Cohen AS, et al. Neonatal vitamin D status and risk of asthma in childhood: results from the D-Tect study. Nutrients. (2020) 12:842. doi: 10.3390/nu12030842

6. Pacheco-González RM, García-Marcos L, Morales E. Prenatal vitamin D status and respiratory and allergic outcomes in childhood: a metaanalysis of observational studies. Pediatr Allergy Immunol. (2018) 29:24353. doi: 10.1111 pai.12876

7. Hart PH, Lucas RM, Walsh JP, Zosky GR, Whitehouse AJ, Zhu K, et al. Vitamin D in fetal development: findings from a birth cohort study. Pediatrics. (2015) 135:167-73. doi: 10.1542/peds.2014-1860

8. Lai SH, Liao SL, Tsai MH, Hua MC, Chiu CY, Yeh KW, et al. Low cord-serum 25-hydroxyvitamin D levels are associated with poor lung function performance and increased respiratory infection in infancy. PLoS ONE. (2017) 12:173268. doi: 10.1371/journal.pone.01 73268

9. Zosky GR, Hart PH, Whitehouse AJ, Kusel MM, Ang W, Foong RE, et al. Vitamin D deficiency at 16 to 20 weeks' gestation is associated with impaired lung function and asthma at 6 years of age. Ann Am Thorac Soc. (2014) 11, 571-577. doi: 10.1513/AnnalsATS.201312-423OC

10. Fort P, Salas AA, Nicola T, Craig CM, Carlo WA, Ambalavanan $\mathrm{N}$, et al. Comparison of 3 vitamin $\mathrm{D}$ dosing regimens in extremely preterm infants: a randomized controlled trial. J Pediatr. (2016) 174:1328. doi: 10.1016/j.jpeds.2016.03.028

11. Al-Beltagi M, Rowiesha M, Elmashad A, Elrifaey SM, Elhorany H, Koura HG. Vitamin D status in preterm neonates and the effects of its supplementation on respiratory distress syndrome. Pediatr Pulmonol. (2020) 55:108-15. doi: 10.1002/ppul.24552

12. Salas AA, Woodfin T, Phillips V, Peralta-Carcelen M, Carlo WA, Ambalavanan N. Dose-response effects of early vitamin D supplementation on neurodevelopmental and respiratory outcomes of extremely preterm infants at 2 years of age: a randomized trial. Neonatology. (2018) 113:25662. doi: $10.1159 / 000484399$

13. Burris HH, Van Marter LJ, McElrath TF, Tabatabai P, Litonjua AA, Weiss ST, et al. Vitamin D status among preterm and full-term infants at birth. Pediatr Res. (2014) 75:75-80. doi: 10.1038/pr.2013.174

14. Matejek T, Navratilova M, Zaloudkova L, Malakova J, Maly J, Skalova S, et al. Vitamin D status of very low birth weight infants at birth and the effects of generally recommended supplementation on their vitamin D levels at discharge. J Matern Fetal Neonatal Med. (2020) 33:378490. doi: 10.1080/14767058.2019.1586873 manuscript as submitted and agreed to be accountable for all aspects of the work.

\section{SUPPLEMENTARY MATERIAL}

The Supplementary Material for this article can be found online at: https://www.frontiersin.org/articles/10.3389/fped. 2021.790839/full\#supplementary-material

15. Onwuneme C, Martin F, McCarthy R, Carroll A, Segurado $\mathrm{R}$, Murphy J, et al. The association of vitamin D status with acute respiratory morbidity in preterm infants. J Pediatr. (2015) 166:1175-80. doi: 10.1016/j.jpeds.2015.01.055

16. Karras SN, Wagner CL, Castracane VD. Understanding vitamin D metabolism in pregnancy: from physiology to pathophysiology and clinical outcomes. Metabolism. (2018) 86:112-23. doi: 10.1016/j.metabol.2017.10.001

17. Miliku K, Vinkhuyzen A, Blanken LM, McGrath JJ, Eyles DW, Burne TH, et al Maternal vitamin $\mathrm{D}$ concentrations during pregnancy, fetal growth patterns, and risks of adverse birth outcomes. Am J Clin Nutr. (2016) 103:151422. doi: 10.3945/ajcn.115.123752

18. Sadeghian M, Asadi M, Rahmani S, Akhavan Zanjani M, Sadeghi O, Hosseini SA, et al. Circulating vitamin D and the risk of gestational diabetes: a systematic review and dose-response meta-analysis. Endocrine. (2020) 70:3647. doi: 10.1007/s12020-020-02360-y

19. Qin LL, Lu FG, Yang SH, Xu HL, Luo BA. Does maternal vitamin D deficiency increase the risk of preterm birth: a meta-analysis of observational studies. Nutrients. (2016) 8:301. doi: 10.3390/nu8050301

20. Holick MF, Binkley NC, Bischoff-Ferrari HA, Gordon CM, Hanley DA, Heaney RP, et al. Evaluation, treatment, and prevention of vitamin D deficiency: an endocrine Society clinical practice guideline. J Clin Endocrinol Metab. (2011) 96, 1911-1930. doi: 10.1210/jc.2011-0385

21. Templin L, Grosse C, Andres V, Robert CD, Fayol L, Simeoni U, et al. A quality improvement initiative to reduce the need for mechanical ventilation in extremely low gestational age neonates. Am J Perinatol. (2017) 34, 759764. doi: 10.1055/s-0037-1598106

22. Dargaville PA, Aiyappan A, De Paoli AG, Dalton RG, Kuschel CA, Kamlin CO, et al. Continuous positive airway pressure failure in preterm infants: incidence, predictors and consequences. Neonatology. (2013) 104:814. doi: $10.1159 / 000346460$

23. Fenton TR, Kim JH, A. systematic review and meta-analysis to revise the Fenton growth chart for preterm infants. BMC Pediatr. (2013) 13:59. doi: 10.1186/1471-2431-13-59

24. Jensen EA, Dysart K, Gantz MG, McDonald S, Bamat NA, Keszler M, et al. The diagnosis of bronchopulmonary dysplasia in very preterm infants. An evidence-based approach. Am J Respir Crit Care Med. (2019) 200:7519. doi: 10.1164/rccm.201812-2348OC

25. Ambalavanan N, Baibergenova A, Carlo WA, Saigal S, Schmidt B, Thorpe $\mathrm{KE}$, et al. Early prediction of poor outcome in extremely low birth weight infants by classification tree analysis. J Pediatr. (2006) 148:438444. doi: 10.1016/j.jpeds.2005.11.042

26. Kazzi SNJ, Karnati S, Puthuraya S, Thomas R. Vitamin D deficiency and respiratory morbidity among African American very low birth weight infants. Early Hum Dev. (2018) 119:19-24. doi: 10.1016/j.earlhumdev.2018.02.013

27. Kim I, Kim SS, Song JI, Yoon SH, Park GY, Lee YW. Association between vitamin D level at birth and respiratory morbidities in very-low-birth-weight infants. Korean J Pediatr. (2019) 62:166-72. doi: 10.3345/kjp.2018.06632

28. Matejek T, Zemankova J, Malakova J, Cermakova E, Skalova S, Palicka V. Severe vitamin D deficiency in preterm infants: possibly no association with clinical outcomes? J Matern Fetal Neonatal Med. (2020) 2021:19. doi: 10.1080/14767058

29. Fettah ND, Zenciroglu A, Dilli D, Beken S, Okumuş N. Is higher 25-hydroxyvitamin $\mathrm{D}$ level preventive for respiratory distress syndrome in preterm infants? Am J Perinatol. (2015) 32:247-50. doi: 10.1055/s-0034-1383849 
30. Shah BA, Padbury JF, Anderson MP, Holick MF, Szyld E, Gordon CM. Vitamin D and associated perinatal-neonatal outcomes among extremely low-birth-weight infants. J Perinatol. (2018) 38:1318-23. doi: 10.1038/s41372-018-0203-y

31. Foong RE, Bosco A, Jones AC, Gout A, Gorman S, Hart $\mathrm{PH}$, et al. The effects of in utero vitamin D deficiency on airway smooth muscle mass and lung function. Am J Respir Cell Mol Biol. (2015) 53, 664675. doi: 10.1165/rcmb.2014-0356OC

32. Phokela SS, Peleg S, Moya FR, Alcorn JL. Regulation of human pulmonary surfactant protein gene expression by 1alpha,25dihydroxyvitamin D3. Am J Physiol Lung Cell Mol Physiol. (2005) 289:L617-626. doi: 10.1152/ajplung.00129.2004

33. Kho AT, Bhattacharya S, Tantisira KG, Carey VJ, Gaedigk R, Leeder JS, et al. Transcriptomic analysis of human lung development. Am J Respir Crit Care Med. (2010) 181, 54-63. doi: 10.1164/rccm.200907-1063OC

34. Mandell E, Ryan S, Seedorf GJ, Gonzalez T, Abman SH, Fleet JC. Maternal vitamin D deficiency induces transcriptomic changes in newborn rat lungs. J Steroid Biochem Mol Biol. (2020) 199:105613. doi: 10.1016/j.jsbmb.2020.105613

35. Lykkedegn S, Sorensen GL, Beck-Nielsen SS, Pilecki B, Duelund L, Marcussen N, et al. Vitamin D depletion in pregnancy decreases survival time, oxygen saturation, lung weight and body weight in preterm rat offspring. PLoS ONE. (2016) 11:e0155203. doi: 10.1371/journal.pone.0 155203
36. Mandell E, Seedorf G, Gien J, Abman SH. Vitamin D treatment improves survival and infant lung structure after intra-amniotic endotoxin exposure in rats: potential role for the prevention of bronchopulmonary dysplasia. Am J Physiol Lung Cell Mol Physiol. (2014) 306:L420-8. doi: 10.1152/ajplung.00344.2013

Conflict of Interest: The authors declare that the research was conducted in the absence of any commercial or financial relationships that could be construed as a potential conflict of interest.

Publisher's Note: All claims expressed in this article are solely those of the authors and do not necessarily represent those of their affiliated organizations, or those of the publisher, the editors and the reviewers. Any product that may be evaluated in this article, or claim that may be made by its manufacturer, is not guaranteed or endorsed by the publisher.

Copyright (C) 2022 Papalia, Samonini, Buffat, Gras, des Robert, Landrier, Pauly and Boubred. This is an open-access article distributed under the terms of the Creative Commons Attribution License (CC BY). The use, distribution or reproduction in other forums is permitted, provided the original author(s) and the copyright owner(s) are credited and that the original publication in this journal is cited, in accordance with accepted academic practice. No use, distribution or reproduction is permitted which does not comply with these terms. 